\title{
PRODUCT CUSTOMIZATION AND GENERATIVE DESIGN
}

\author{
Laura Trautmann \\ PhD student, Budapest University of Technology and Economics, \\ Faculty of Mechanical Engineering, Department of Machine and Product Design \\ 1111 Budapest, Müegyetem rkp. 3., e-mail: trautmann.laura@gt3.bme.hu
}

\begin{abstract}
Parametric design is essentially a generative design that can be created using a computer and mathematical relationships. In a process-oriented way (instead of changing the shape), we modify the components' parameters that make up the shape, resulting in a new look. Because manipulations' consequences can be seen immediately, the development of product families and new product variants can be implemented quickly. With the help of parametric design, customizing the product and increasing customer satisfaction is more efficient, as several successful projects have already shown in automotive industry, aircraft manufacturing, architecture, jewelry manufacturing, etc.
\end{abstract}

Keywords: Generative design, Customization, Algorithm, Parametric design

\section{Introduction}

Studies have shown [1] that product customization is important to reach more customer satisfaction. For example, Deloitte found out that one out of five customers is willing to pay $20 \%$ more for a unique, personalized product [2]. This is why it has become a business strategy in many fields, from shoe design to vehicle features.

Parametric or generative design (also known as algorithmic design) can have a great future because by using it, the designer can provide customers with personalized, unique pieces. Generative design essentially means design using a computer and mathematical relationships. The result is generated by algorithms. Unlike the traditional design method, the design processes can be controlled step by step, and the consequences of the manipulation can be seen immediately. Thanks to the new approach, several versions of a product can be carried out extremely quickly. It is because changing a parameter transforms the whole body.

In the course of the article, the essence of generative design is described, and its features and advantages are presented by showing industrial examples.

\section{Generative design}

In generative design instead of the designer drawing the product he envisions, it is sufficient to specify the requirements set for the product (such as material properties, manufacturing process, cost, etc.) for the computer, and the software creates the possible solutions [3] [4].

Take an example: the designer would like to design a chair. Instead of drawing a chair and then playing with its shape, he can give the computer how much weight it can support, how much weight the chair itself should be, how much it should cost, and what material it should be made of. The computer can produce thousands, if not millions, of options that meet the criteria. From the variants, we can choose the solution that meets the most important requirement (Figure 1). 

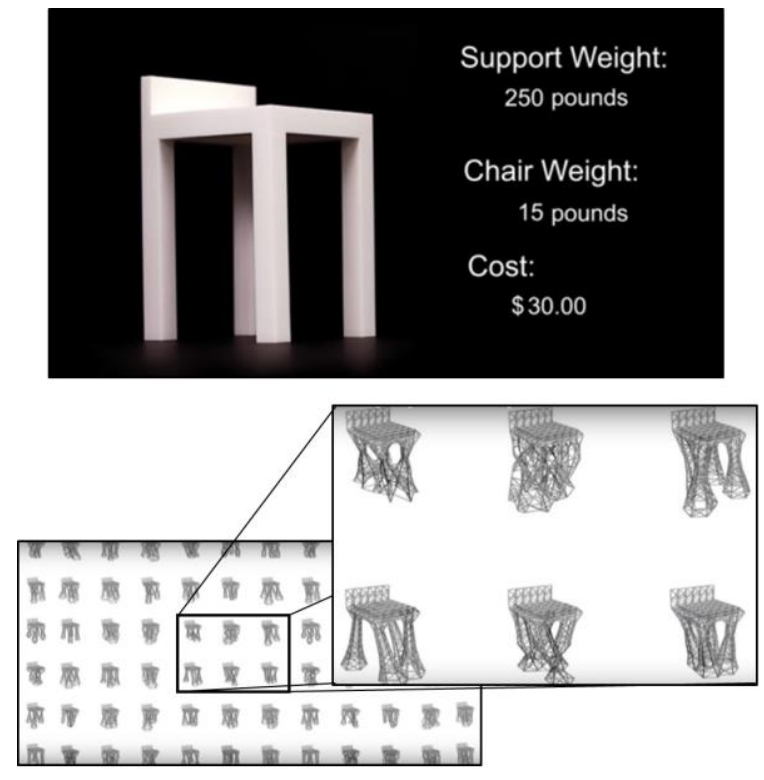

\section{ENTERING \\ PARAMETERS}

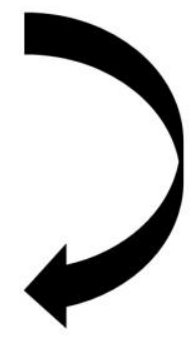

GENERATING

SOLUTIONS

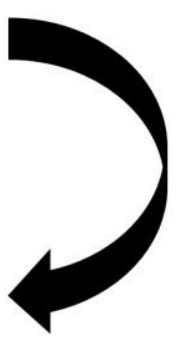

SELECTING

Figure 1 Steps of the generative design based on Jeff Kowalski's performance [4]

Generative design has several advantages, some of which are:

- Among other things, a shape may be created in a way that the designer would not have imagined,

- time can be saved because while we are able to create an idea, the computer is creating thousands,

- and combined with additive manufacturing, such a complex shape and optimized inner mesh can be created that would be impossible to achieve with traditional manufacturing methods.

\section{Car manufacturing}

An average car consists of about 30,000 parts. Manufacturing and assembling them is a very complex process [5], so the use of generative design can be particularly advantageous in automotive manufacturing.

General Motors and Autodesk plan to create a lighter and stronger car with fewer parts with generative design. Engineers enter the parameters associated with each auto part into the program, and an algorithm creates and tests the shape that can be added to them [5]. The next benefits would have a car created in this way [5]: 
- would reduce the weight of car parts,

- the components could be combined or manufactured with 3D printing,

- this can also reduce costs.

It can be seen that technology fundamentally changes the way engineering works because instead of developing geometric shapes, specifying the parameters is necessary, which generates up to millions of potential solutions [6].

Innovation in the automotive industry was also the first generatively designed chassis created by the Hack Rod team [7] (Figure 2). The team has replaced the traditional manufacturing approach using generative design, virtual reality (VR), 3D printing and the cloud-based supply chain [7].

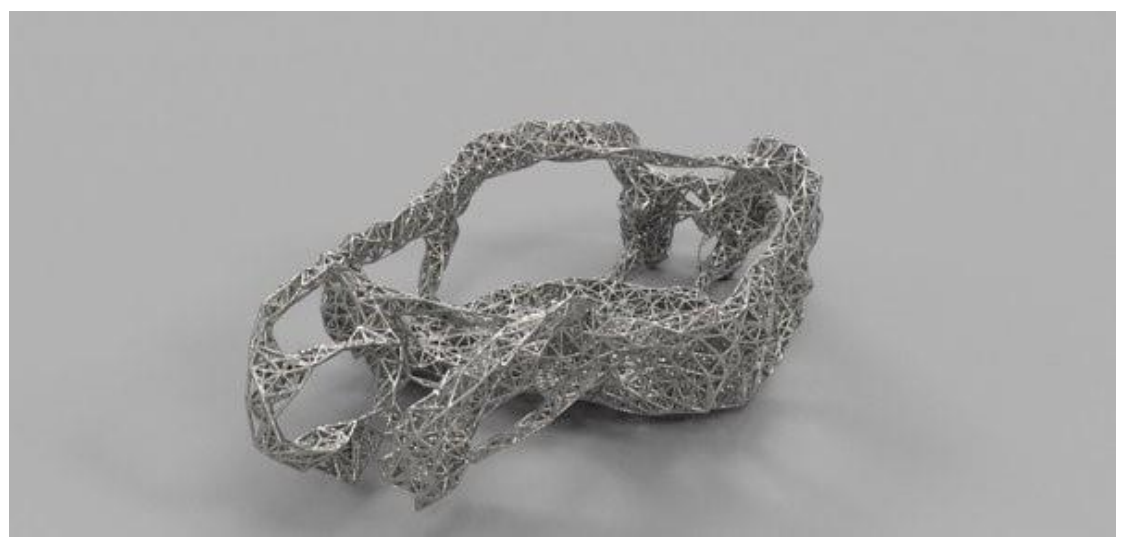

Figure 2 The first chassis with generative design [7]

\section{Aircraft manufacturing}

Generative design is already used by Airbus, which can be considered one of the most famous aircraft manufacturers [8]. With this design method, "We can generate literally tens of thousands of design iterations, compared with the manual process which could generate maybe a dozen." [9] said David Benjamin, director of The Living, a company that collaborated with Airbus, Autodesk, and APWorks [10] to create the new cabin partition for the A320 (Figure 3).

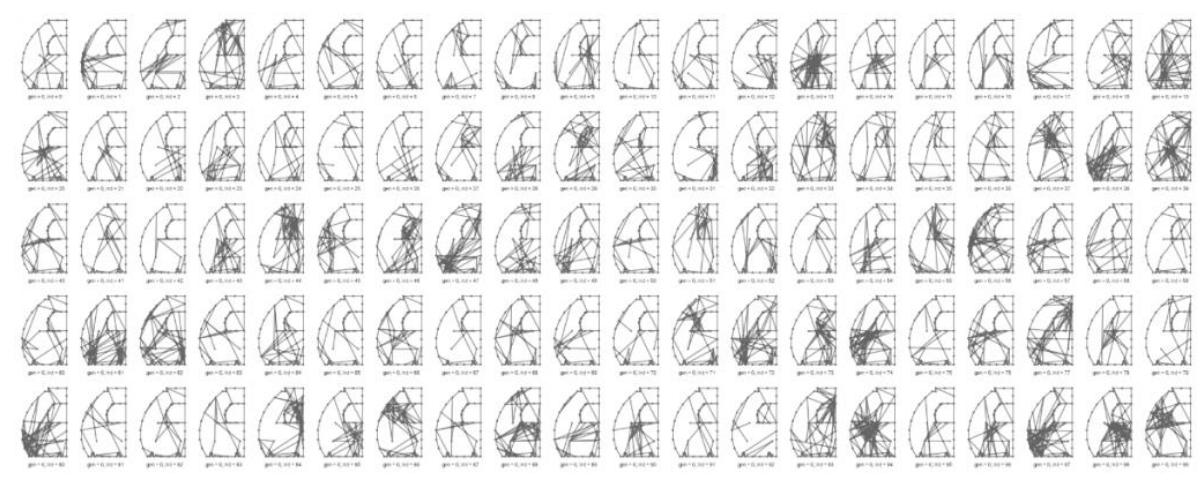

Figure 3 Generationally designed versions for the cabin partition [9]

The new version is $55 \%$ lighter than the original part, and also it is more resistant [11]. 


\section{Topological optimization}

Another application of generative design is topological optimization, in which we change the body's internal structure to make it lighter and more flexible.

An example of this is a running shoe developed by Under Armor (Figure 4) with a 3D printed sole. Thanks to its light and flexible design, the shoe fully adapts to the athlete's running style [12].

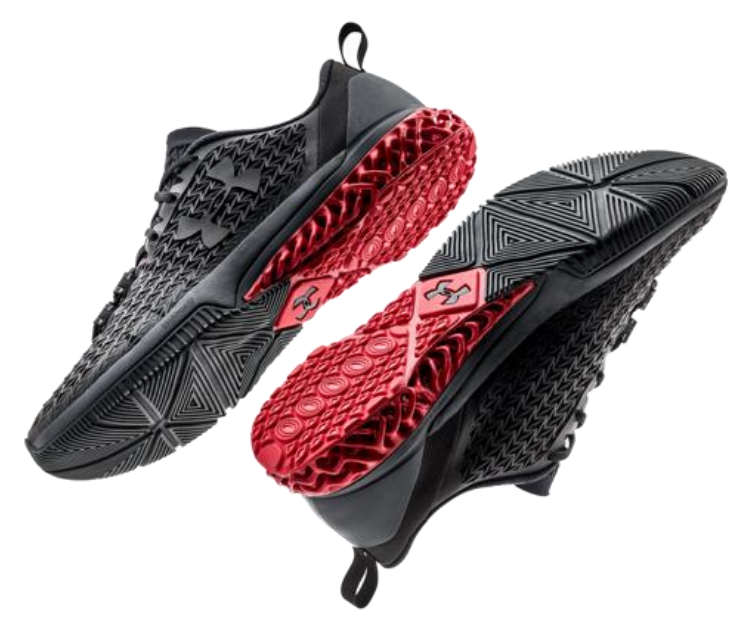

Figure 4 3d-printed shoe [12]

Another example is a skateboard created by Philipp Manger (Figure 5), which has made by its design much easier and faster [13].

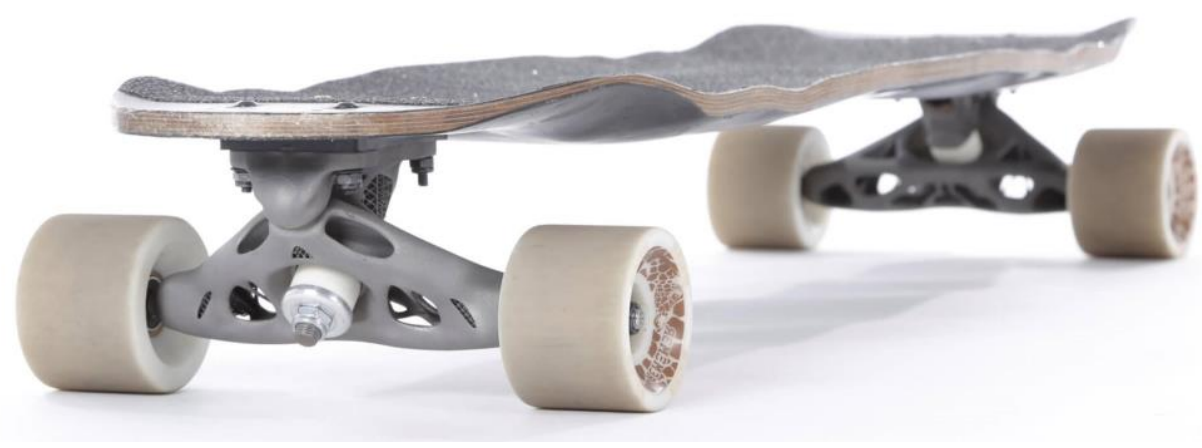

Figure 5 Skateboard created by Philipp Manger [13]

\section{Architecture}

In the early 20th century, Gaudí used parametric models to design buildings, and as technology evolves, we can see more and more examples of buildings created with generative design [14] [15], for example, the Metropol Parasol shown in Figure 6 was also made on such a principle. 


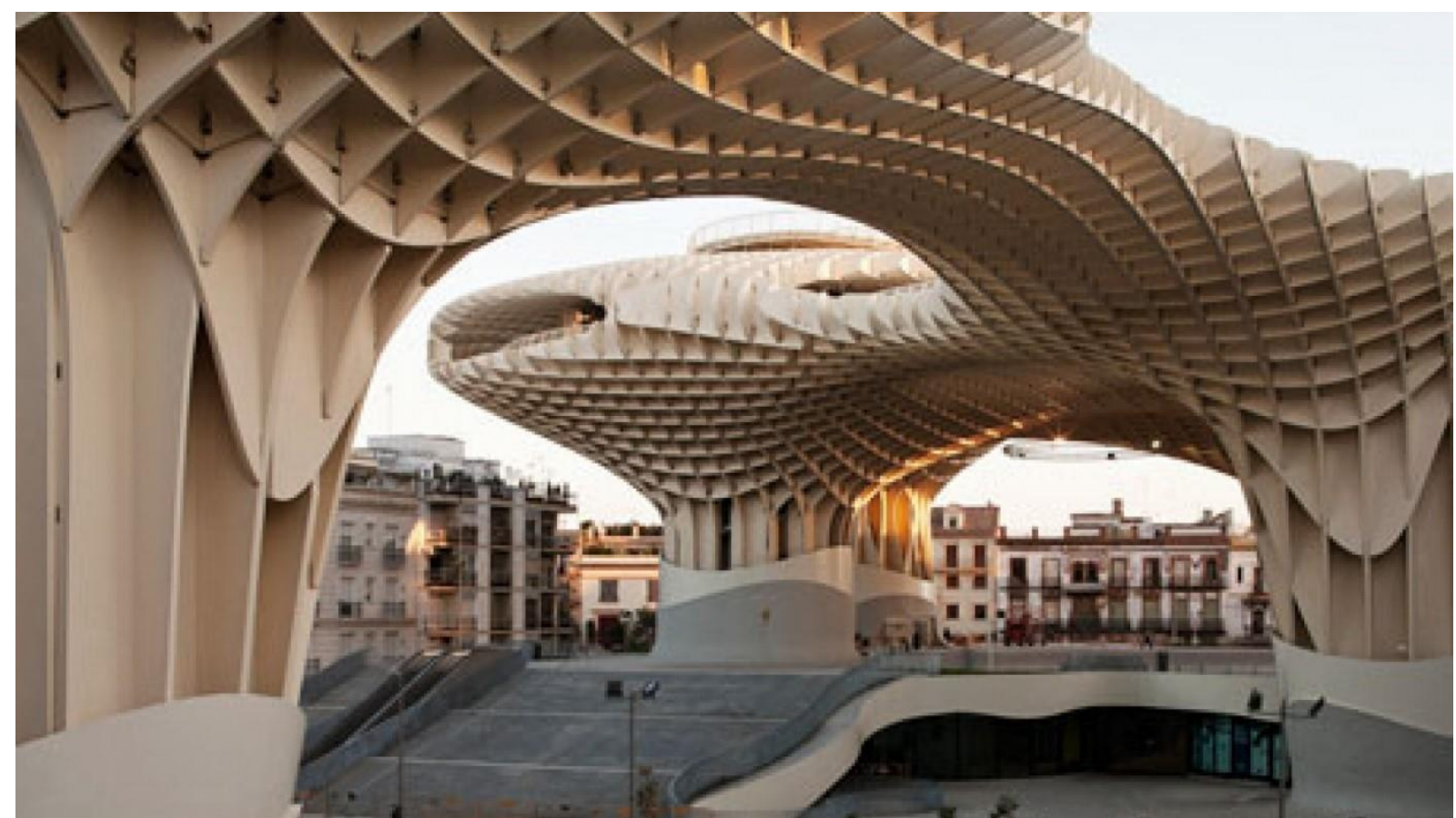

Figure 6 Metropol Parasol [15]

Another example is British Petrol Headquarters designed by Adams Kara Taylor, whose roof structure can be seen in several variations in Figure 7. During the parametric design, both aesthetic and quality aspects were taken into account. Criteria included, for example, getting as much sunlight as possible into the yard and getting into the building [16].

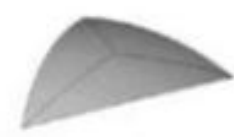

Option 1

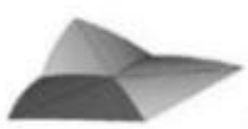

Option 7

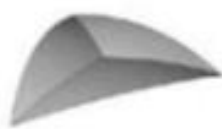

Option 13

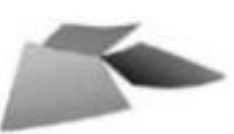

Option 2

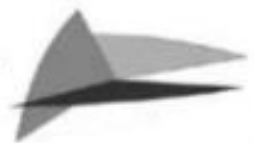

Option8

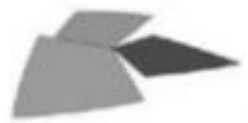

Option14

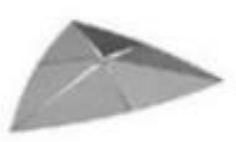

Option3

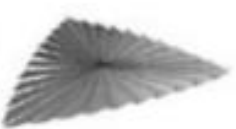

Option9

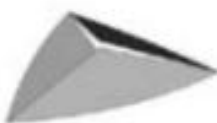

Option 15

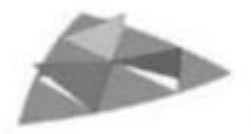

Option4

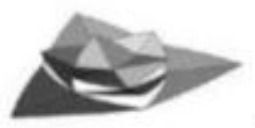

Option 10

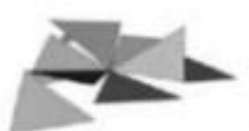

Option 16

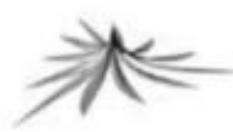

Option5

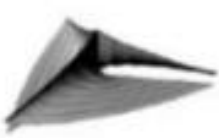

Optionl1

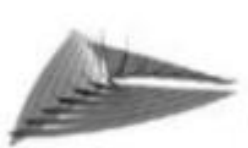

Option17

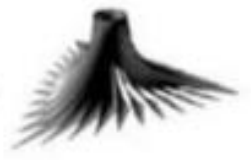

Option6

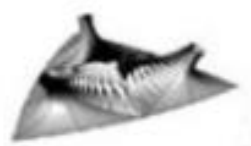

Option 12

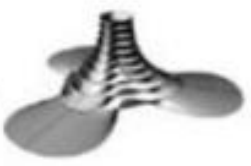

Option 18

Figure 7 British Petrol Headquarters in Sunbury by Adams Kara Taylor [17] 


\section{Other industries}

\subsection{Jewelry}

There is an application called Fusilli that generates bracelets using an algorithm (Figure 8). Combined with selective laser sintering, the program creates flexible and lightweight bracelets that cannot be implemented with traditional product design tools [18].
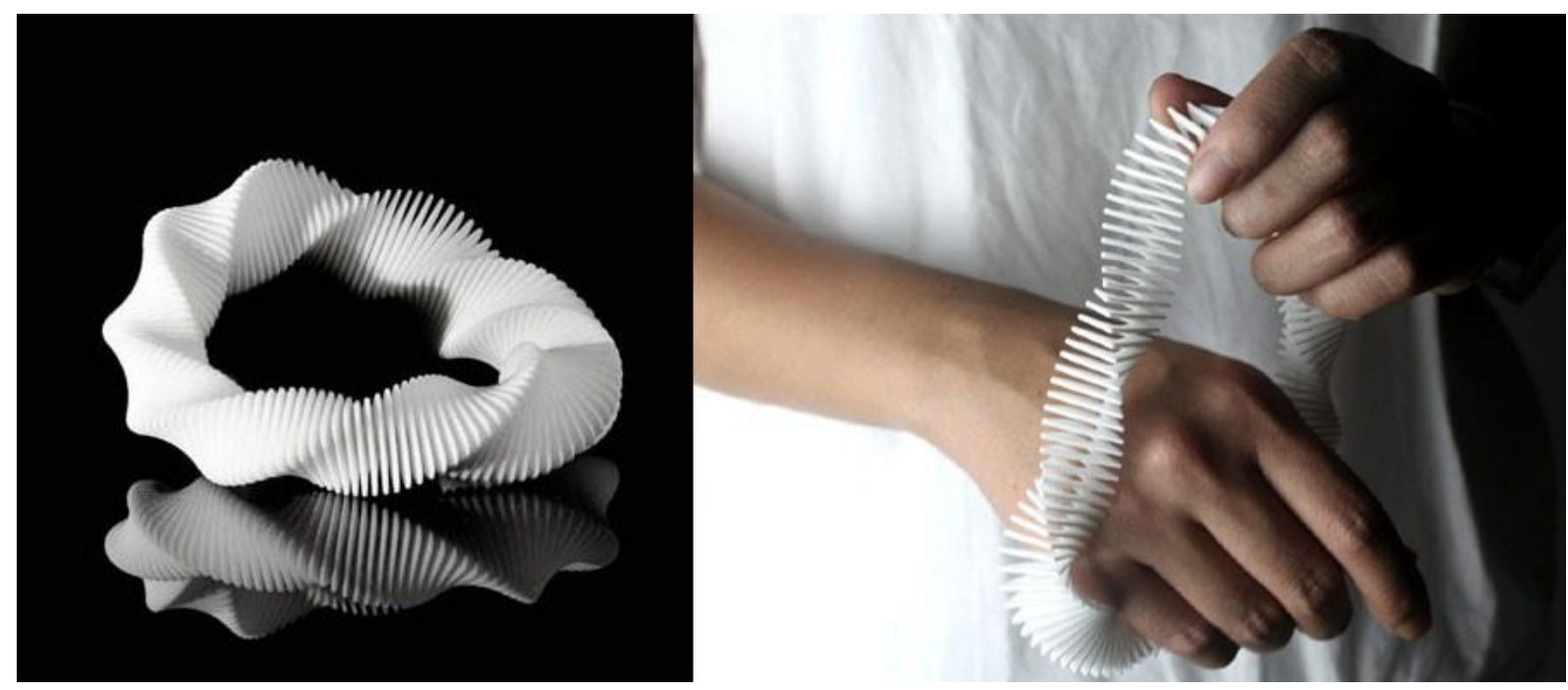

Figure 8 Bracelet created by Fusilli App [18]

Generative design is used in several companies to make jewelry. For example, with Kinematics, Cell Cycle, and Radiolaria applications as custom design tools, we can create our fully personalized necklaces, rings, bracelets, etc., in real-time. These applications are provided by a company called Nervous System (https://n-e-r-v-o-u-s.com/labs/). (The company researches patterns and shapes found in nature, based on which mathematical models are set up. The completed simulations can be used to create unique products. Personalized products are created by 3D printing [19].)

\subsection{Clothing}

Kinematics Cloth is a web application (https://n-e-r-v-o-u-s.com/ kinematicsCloth/), where buyers can design clothes for themselves, modifying its 3D display. The cloth is made with 3D printing, and the customer's body scan file can be imported for design, making the garment fully personalized. You can give the cloth the shape of the base, and then further shape it, adjust the garment's length, fall, etc., using different grips in real-time. The pattern and its density can also be adjusted. The textile structure can also be specified separately, the location of which can also be specified on the clothing, we can combine it as desired (Figure 9). 


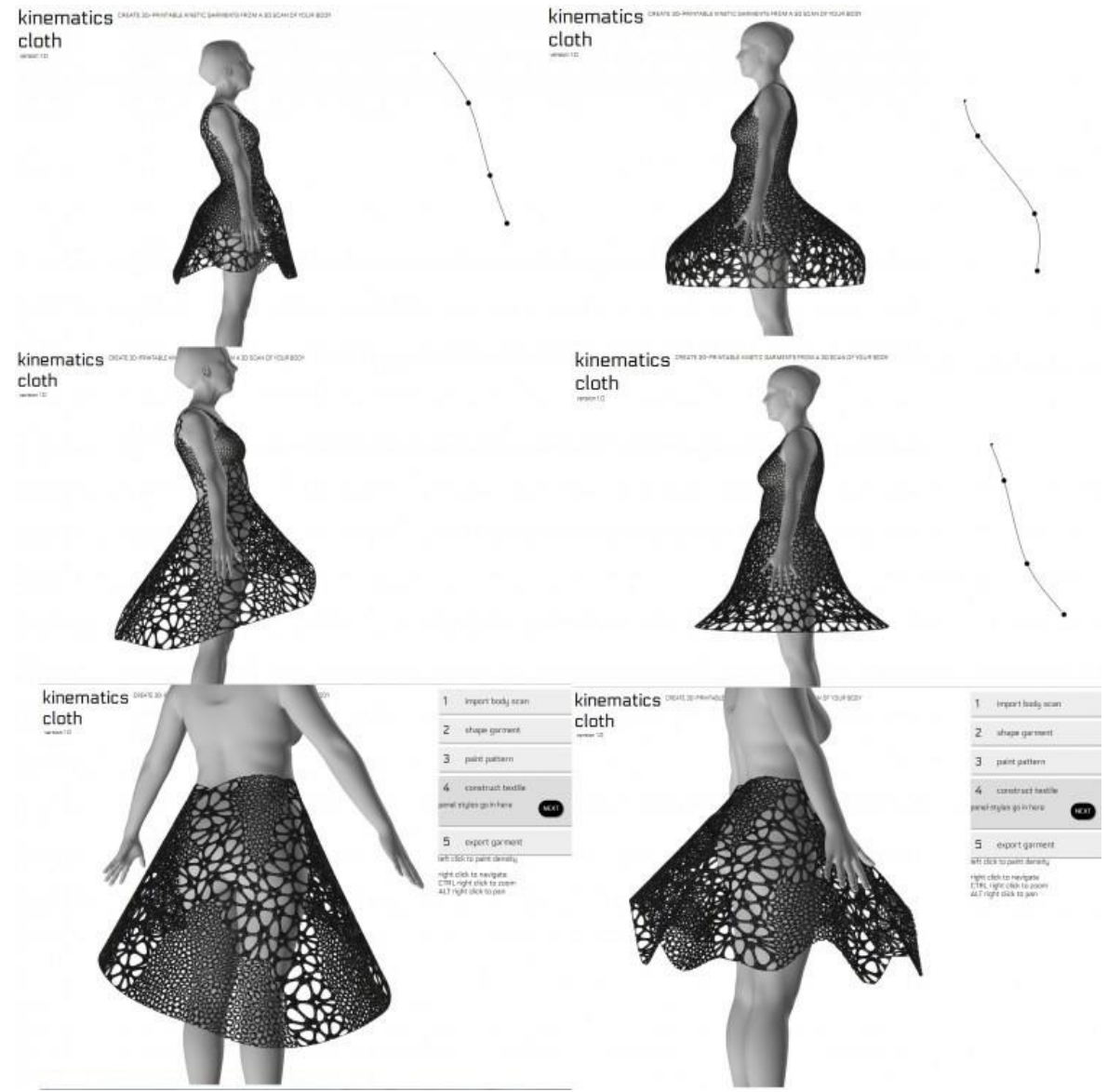

Figure 9 Kinematics Clothing Application [20]

\subsection{Game}

Also developing by the Nervous System is a game called Generative jigsaw puzzle (https://n-e-r-v-ou-s.com/customPuzzle/), where each puzzle has a unique picture and unique pieces (Figure 10).
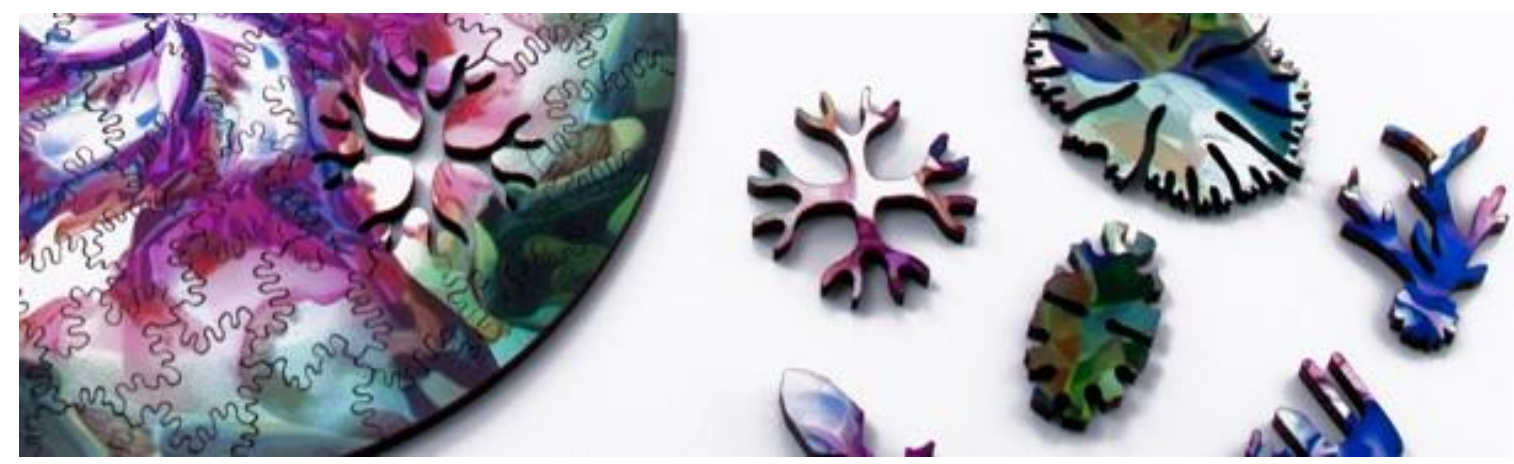

Figure 10 Generative jigsaw puzzle [21] 


\section{Conclusion}

It can be seen that generative design is applied in many areas. In addition to mechanical design, this design approach also opens up new possibilities for architects and product designers, and nowadays, more and more advanced software support is also available.

Basically, generative or parametric design can allow the user to be the designer himself, so he can choose from infinite variations based on his taste, which could increase consumer satisfaction.

\section{Acknowledgements}

The research reported in this paper and carried out at BME has been supported by the NRDI Fund (TKP2020 NC, Grant No. BME-NCS) based on the charter of bolster issued by the NRDI Office under the auspices of the Ministry for Innovation and Technology.

\section{References}

[1] Coelho PS, Henseler J (2012) Creating customer loyalty through service customization. European Journal of Marketing https://doi.org/10.1108/03090561211202503

[2] Fenech C, Perkins B (2015) The Deloitte Consumer Review. Made-to-order: The rise of mass personalisation. Deloitte Development LLC pp 1-20. https://www2.deloitte.com/content/dam/Deloitte/ch/Documents/consumer-business/ch-enconsumer-business-made-to-order-consumer-review.pdf, (accessed: 23.02.2021)

[3] Autodesk (2020) Generative Design. https://www.autodesk.com/solutions/generativedesign, (accessed: 23.02.2021)

[4] Kowalski J (2016) Performance: The Future of Making Things: Generative Design. https://www.youtube.com/watch?v=E2SxqUvtpIk\&ab_ channel=Autodesk, (accessed: 23.02.2021)

[5] Schwab K (2018) GM And Autodesk Develop 3D-Printed Car Parts. CoDesign. https://www.fastcompany.com/90170842/gm-and-autodesk-develop-3d-printed-car-parts, (accessed:23.02.2021)

[6] FRE3DEE (2018) A General Motors és a generatív tervezés. FRE3DEE. https://freedee.blog.hu/2018/05/09/a_general_motors_es_a_generativ_tervezes, (accessed: 23.02.2021)

[7] Varinex (2018) A generatív tervezés az egyedi autógyártásban. CadStudio Gépészeti tervezés. https://cad.cads.hu/generativ-tervezes-az-egyedi-autogyartasban/, (accessed: 23.02.2021)

[8] Varinex (2018) A generatív tervezés a gépipar jövője. CadStudio Gépészeti tervezés. https://cad.cads.hu/generativ-tervezes-a-gepipar-jovoje/, (accessed: 23.02.2021)

[9] Moutch-Hou M (2015) Airbus Enlists Autodesk to Design Mold-Inspired, 3d Printed Aircraft Partition. 3D Printing Industry

[10] Medlock K (2016) Airbus starts 3D-printing airplane parts in collaboration with Autodesk, APWorks and The Living. Inhabitat. https://inhabitat.com/airbus-starts-3d-printing-airplaneparts-in-collaboration-with-autodesk-apworks-and-the-living/, (accessed: 23.02.2021) 
[11] Rhodes M (2015) Airbus' Newest Design Is Based on Bones and Slime Mold. Wired. https://www.wired.com/2015/12/airbuss-newest-design-is-based-on-slime-mold-and-bones/, (accessed: 23.02.2021)

[12] Brown P (2016) Under Armour Changes the Footwear Game with Generative Design and 3DPrinted Shoes. Redshift. https://redshift.autodesk.com/3d-printed-shoes/, (accessed: 23.02.2021)

[13] Turney D (2018) Thrashing the Future of Design with Topology Optimization and Skateboard Trucks. Redshift. https://redshift.autodesk.com/skateboard-trucks-topology-optimization/, (accessed: 23.02.2021)

[14] Alvarado RG, Gottlieb AL, Cendoya P, Salcedo P (2013) Parametric development of variable roof structures with central supports (Tulips). Nexus Network Journal 15(2):257-269 https://doi.org/10.1007/s00004-013-0153-9

[15] Argyriades M (2011) Metropol Parasol // The World's Largest Wooden Structure. https://www.yatzer.com/Metropol-Parasol-The-World-s-Largest-Wooden-Structure-J-MAYERH-Architects, (accessed: 23.02.2021)

[16] Dino I (2012) Creative design exploration by parametric generative systems in architecture. METU Journal of Faculty of Architecture 29(1):207-224 https://doi.org/10.4305/METU.JFA.2012.1.12

[17] Sakamoto T (2008) From control to design: parametric/algorithmic architecture. Actar-D ISBN 978-8496540798

[18] Zheng, C. (2020) Fusilli App. https://www.sde.nus.edu.sg/did/studentprojects/platforms/generative-design/, (accessed: 23.02.2021)

[19] System N (2020) art + science + technology. https://n-e-r-v-o-u-s.com/labs/, (accessed: 23.02.2021)

[20] Staver M (2014) Nervous System at Solid. https://n-e-r-v-o-u-s.com/blog/?p=5557, (accessed: 23.02.2021)

[21] Scholz A (2012) Generative Jigsaw Puzzles - Nervous System toys with a classic enigma. Creative Applications Network. https://www.creativeapplications.net/processing/generative-jigsawpuzzles-nervous-system/, (accessed: 23.02.2021) 